\title{
Clustering for Economic Sustainability of the Traditional Jewellery Artisans of Ranthali: Challenges \& Intervention
}

\author{
Mita Nath Bora ${ }^{1}$
}

\begin{abstract}
The rural jewellery artisans of Ranthali, a remote village in Assam, India, famous for its traditional gold jewellery craftsmaking, had been facing a dwindling business for several decades, inspite of such craftsmanship being a flourishing rural industry of the region till the 18th \& 19th century. In the year 2010, under the MSE-CDP scheme, livelihood interventions were made through clustering these artisans, in an effort to revive them and make them economically sustainable. This research paper presents an analysis of a study conducted amongst the artisans of Ranthali to assess (a) whether cluster interventions helped enhance artisans' livelihood and income using the livelihood model 'The Coolie's Framework' and; (b)whether sustainable economic outcome has been achieved. The study relied mostly on primary data sources collected on the field. It concludes that though clustering for economic growth has several challenges, however, with a holistic approach and continuous multiple interventions over several years, certain successful changes were made. In the case of Ranthali, today, 300 artisans are into jewellery making as their primary occupation from the previous number of $150 \&$ the ecosystem created has helped all 300 artisans to have their own household units with 20 of them having formal registered units.
\end{abstract}

Keywords: Clusters, Traditional Artisans, Sustainability, Holistic Approach, Ecosystem

\section{Introduction}

Jewellery since time immemorial has remained 'owner's pride and neighbour's envy.' The success story of Indian gold ornaments manufacturing industry lies in the 4.64 million highly skilled workforces (Foundation, 2019) dedicated to the growth of this sector. The art of jewellery making in Assam ${ }^{1}$ was part and parcel of the rich culture and tradition of the region since time immemorial. In the 4th century, about 350 A.D the rich jewels and gold ornaments worn by the king of Kamrupa ${ }^{2}$ used to be the objects of admiration of the kings of other parts of India. The gold emporium at Suvarnakudya ${ }^{3}$ (Son-Kuriha near Hajo) was the meeting place of merchants from different parts of India, as the gold of Kamrupa extracted by washing the river sand was considered to be the purest and the best in quality (Gait, 1926).

Gold washing and manufacture of gold jewellery were two important ancient industries in Assam \& gold dust was abundantly found. Nearly all the tributaries of the Brahmaputra were auriferous and gold was washed from the innumerable streams that

1 is a state in northeastern India, situated south of the eastern Himalayas along the Brahmaputra and Barak River valleys

2 the first historical kingdom of Assam

3 ancient Kamrupa 
intersected the land. And although gold washing in Assam steadily declined, the goldsmith continued to occupy a prominent place in the village society. In many rural villages a few of these artisans still pursued these traditional occupation, handed down to them by their ancestors through generations, although at a subsistence level. Inspite of the indigenous jewellers exhibiting considerable amount of skill and artistic refinement in making golden ornaments, the craft is practiced only at a few selected places like Nagoan, Jorhat and Barpeta ${ }^{4}$ presently. Rural artisans finds it difficult to survive in the global advanced and competitive market.

However, the artistic work, the skill, aesthetic value of handmade original products could neither be replaced nor produced by machine, hence the demand for these products still exist. Considering that the rich tradition of indigenous crafts and industries of Assam has immense scope, and that these can play a pivotal role in the regional economy in terms of economic growth and employment, the growth and sustained development of these small sector industries were sought and several efforts have been made at various stages to revive them. Realizing that they alone cannot stand strong and competitive, the organization of these industries into some kind of homogeneous cluster was seen to be an alternative. One such cluster effort has been the introduction of the Micro Small Enterprise Cluster Development Programme (MSE CDP) scheme of the Ministry of Micro, Small and Medium Enterprises (MSME) in 2007 (DCMSME, June, 2015) with a focus to not only revive the artisan community but also to provide a sustainable livelihood through use of the skill, technological support, exposure to the national and internal market, backward and forward linkages and thus make them successful micro enterprises.

To understand the impact of cluster intervention for livelihood enhancement and economic sustainability of the jewellery artisans a research study was conducted amongst the traditional jewellery artisans of Ranthali village of Nagaon, Assam to assess (a) whether cluster interventions helped enhance artisans' livelihood and income using the livelihood model 'The Coolie's Framework' and; (b)whether sustainable economic outcome has been achieved through two broad research questions.

\section{Theoretical Background}

\subsection{Clusters}

Clusters are defined to be concentration of units in a given geographical location producing same or similar types of products and facing common opportunities and threats. The concept of cluster was first propounded by Alfred Marshall, the English economist (Marshall, 1890). During the 1990s, cluster development became a topic of interest for an increasing number of developing countries which saw in clustering a strategy to overcome growth constraints of small informal firms (Beddig, 2008). Cluster development has been undertaken in more than 50 countries across the world (UNIDO, 2015). India has more than 6400 clusters (Singh, 2010) with the northeast having several clusters which are basically artisan handloom and handicraft clusters.

Clustering has been an age old phenomenon in India (Clusters, 2006). Mahatma Gandhi,

\footnotetext{
${ }^{4}$ present cities and Towns in Assam
} 
one of the early livelihood thinkers of $20^{\text {th }}$ century, with a deep concern for both the poor and for sustainability suggested developing local economies by promoting interdependant activities, as a member of a mutually supportive community, eventually leading to 'gram swaraj' 5 . Such efforts were termed as cluster development that supports a large number of livelihoods that keeps a person meaningfully occupied in a sustainable manner with dignity.

\subsection{Sustainability}

It is well known that the concept of sustainability is multifaceted, and that its use varies largely within different contexts. Gomis et al refer specifically to the idea of 'sustainable development' when using the term 'sustainability', and points out that 'sustainable business', 'sustainable technology', 'sustainable agriculture', 'sustainable economics', etc., are all buzzwords of the literature today (Gomis, Parra, Hoffman, \& McNulty, 2011). In fact, 'the precise meaning of sustainable, and what it embraces, varies depending upon who is using it and in what context' (Bell \& Morse, 2008). According to the American Heritage Dictionary, 'to sustain' means to keep in existence, to supply with necessities, to support from below, to encourage, and to maintain competently (Dictionary, 2016).

In context to cluster, sustainability would mean to measure the activities carried out for means improving lives through good works. In fact, most social change makers exist to achieve this goal and sustain a positive impact over time. Historically, social sector used traditional measures of success, such as the number of beneficiaries served or the number and type of activities undertaken. Increasingly, however, sustainability is linked with doing 'what works' and discontinuing programs that don't achieve their goals, to direct resources to activities that produce results and away from those that do not. However, since technically, economic sustainability encompasses financial costs and $\underline{\text { benefits, }}$ economic indicators that are considered in this paper are factors like income, investment capacity, unit formalization, bank account opened, sales and profit.

\section{Area under Study}

The Ranthali jewellery making cluster is located in Nagaon district of Assam. This cluster originally comprised of one village with about 20 households from the SC \& $\mathrm{OBC}^{6}$ communities who were engaged in jewellery making. The tradition of jewellerymaking was present in the Ranthali cluster many centuries back. Craftsmanship of gold jewellery in Ranthali, the delicate and conventional designing traits of the ornaments found in the cluster are a unique feature of the age-old existence of jewellery making profession in the cluster passed on through generations. The 'karigar'7 inherits techniques and skills from his forefathers, which he perfects to give traditional jewellery a uniqueness of its own. Initially there were about 20 artisans in the cluster who took to jewellery making profession. These artisans faced several challenges of limited product

\footnotetext{
${ }^{5}$ village self-rule or freedom at the village level

${ }^{6}$ schedule caste \& other backward communities, two different caste/category prevalent in India

7 traditional artisans
} 
range, inferior quality, non availability of quality raw material, undercutting of prices, presence of too many middlemen, lack of finishing, packaging, etc. And though they had good commercial orientation, yet were unable to sustain them and work in an organised form.

In 2012, IIE as an implementing agency under Ministry of Small and Medium Enterprises (MSME), initiated intervention in several areas, such as social capital building/institution building, design inputs, product diversification, introduction of appropriate technology, market linkage, quality enhancement, introduction of gemstone cutting \& polishing, etc and created multiple convergences. More and more artisans were encouraged to take up their traditional art form and keep it alive while also incorporating modern designs and variety to keep with the demands of the times. Slowly over the years the trade of jewellery proved to be a profitable business and more number of households in the Ranthali village undertook the jewellery making profession, thus making the cluster grow. Presently, every 6th household in the village has a jewellery manufacturing unit which makes it an important source of livelihood for them.

\section{Study Methodology}

The study of the Ranthali Jewellery Cluster was conducted under a mixed methodology using tools like semi structured interviews, questionnaires and discussions. Most of the data collected was from primary sources. The questionnaires were used for the household level jewellery manufacturing units and interviews for informal group discussions with the artisans, association members etc. A total of 200 respondents were surveyed during the research. Other respondent included the related government department officials like the District Industries and Commerce department (DIC), institutional support partners like Indian Institute of Entrepreneurship (IIE) National Institute of Design (NID), Development Commisioner (DC-Handicraft), Development Commissioner Micro Small and Medium Enterprises (DC-MSME), credit service providers (Banks \& Financial Institutions). Meetings were held with the village headman and cluster Special Purpose Vehicle (SPV) members. All interviews were conducted orally and recorded in notes, which were later transferred and documented digitally. The data collected were analyzed along certain defined parameters so that the study conducted can be evaluated on the basis of effectiveness in terms of income, investment, productivity, order, sale, etc.

\section{Cluster Intervention Analysis vis-a-vis Economic Sustainability}

\subsection{Assessment using Coolie's Framework}

One of the important aspect of assessing a cluster's success and sustainability isunderstanding the interventions undertaken in the cluster. Professor Michael Eugene Porter who proposed the term 'cluster' in his book 'The Competitive Advantage of Nations' (Porter, 1990) developed a framework to analyse industrial clusters (Porter M. E., 1998). Drawing analogy from the same, Vijay Mahajan and Thomas Fisher ${ }^{8}$ helped

\footnotetext{
8 Industrial sub-sector researchers
} 
Sankar Dutta, Livelihood expert, to adapt a new Coolie's framework (Datta, Mahajan, \& Thakur, 2004) for analysing livelihood intervention choices in clusters. The two main elements of the framework are the internal and external context of the livelihoods of the target segment. In this content, it is the internal and external context of the Ranthali Jewellery Cluster.

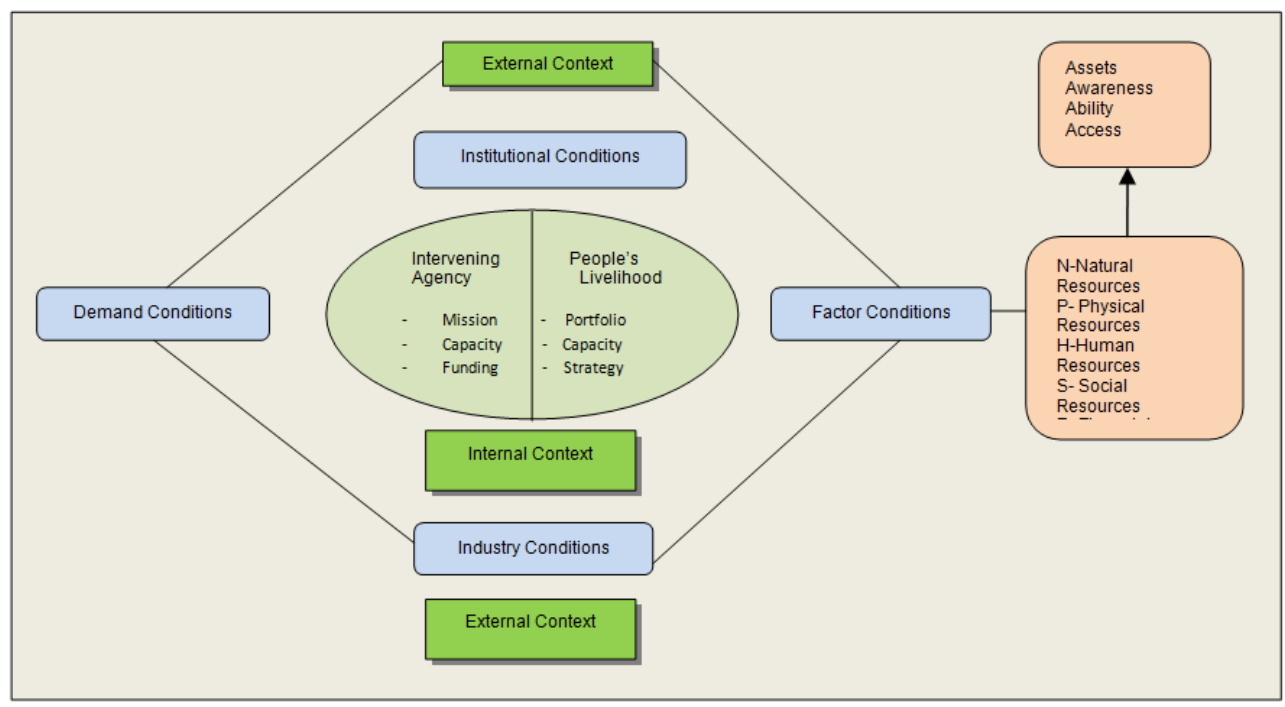

Figure 1: Coolie's Framework

\subsubsection{Internal Context - People and the Intervening Agency}

The internal context involves people whose livelihood are to be promoted, their livelihood portfolio and their capacities. In the case of the Ranthali Cluster the people are the jewellery artisans, the target group who are the vital element for intervention. As the artisans of Ranthali village had jewellery as one of their main livelihood it was considered important for cluster interventions. The same was dove-tailed to create incremental benefits around this present livelihood. The 'livelihood portfolio' of these jewellery artisans also included other economic activities like paddy cultivation, dairy farming and small shops. In terms of the 'livelihood capacities', it is found that there exits a strong factor with the family members helping each other and being involved in the jewellery business. Almost, each member of the family has knowledge and skill of jewellery making and acts as an extra hand amongst the workers in the household unit. These artisans have strong entrepreneurial ability and commercial orientation. However, they were averse to change, skeptical and resisted any new initiative. Only with continuous persistent effort the artisans accepted to work on product diversification, new designs and have now adopted multiple strategies over the years.

The Intervening/Implementing Agency is also an important factor of the internal context and its capacity, mission, objective and manpower plays a great role. IIE has been selected as the implementing agency for this cluster by the Ministry of MSME and IIE because of its presence in the region and its experience of handling cluster programmes in several hilly states of the northeast region was considered a right choice. 
With its headquarter in Guwahati ${ }^{9}$, Assam, which is at a distance of $129 \mathrm{kms}$, the Ranthali cluster got good focus and attention after the cluster formation in 2012 and has over the years grown in strength.

\subsubsection{External Context - Factor, Demand, Industry and Institutional Conditions}

The external context consists of four elements that influence livelihood choices : the Factor Conditions, Demand, Industry and Institutional Conditions.

\subsubsection{Factor Conditions}

In Ranthali cluster the factor conditions of human (good number of manpower available in each household (300 artisans in the village) and good labour force (412 workers working in the units) were present. Natural conditions (availability of raw material nearby from wholesale dealers and raw material suppliers in the nearby markets) were present. Social capital of this cluster is also strong as 20 Self Help Groups (SHG) exists in the village of which most of the artisans are members. After intervention a strong SPV (Ranthali Asamiya Gahana Karikori Santha) was formed and convergences with other organisation/institutions like DIC Nagaon, DC(Handicraft), Assam Gramin Vikash Bank (AGVB), etc were created. Constraints existed in terms of the physical conditions as the artisans lacked proper infrastructure and had been carrying out work from their house units. They were also using outdated tools and machinery as they feared that use of modern machineries might lead to mechanization of their products and lose the traditional touch and skill. However, with technical intervention, the artisans during their exposure visits to Jaipur Gems and Jewellery Centre, Guwahati and several trainings learnt to use new tools, stone setting techniques, kundan ${ }^{10} /$ gold foil setting, etc that were essential to stay competitive in the market.

In terms of the Assets, Awareness, Ability and Access to the natural resources, the Ranthali jewellers are aware of the importance of the natural assets in the region and how to use them in their livelihood opportunities. At the same time they also posses the ability, the required knowledge and skill of good jewellery works, and therefore have a strong and favourable conditions. Though there were initial challenges of access to quality raw material, today the cluster has readily available raw materials from wholesellers and raw material suppliers in the nearby market due to the backward integration created through exposure interventions.

\subsubsection{Demand Conditions}

Another external context that required attention is the demand factor for the jewellery. The artisans were usually involved in selling their products on their own and in nearby villages only, mostly dependent on the wholesale traders/retail showrooms for sale of their products while having no market outside the state. Continuous intervention helped the cluster showcase and sell their products at India International Trade Fair (IITF), International Gift Fair, Craft Bazaar, GramShree Mela, Delhi Haat, Suraj Kund

\footnotetext{
${ }^{9}$ Capital city of Assam

10 is a traditional form of Indian gemstone jewellery involving a gem set with a gold foil between the stones and its mount, usually for elaborate necklaces
} 
Mela, etc and create new market for themselves. Slowly, most of the handmade jewellery ornaments found their way to big showrooms within the district, with a major chunk being sold in showrooms and wholesale traders in Jorhat, Guwahati, Lakhimpur, Tezpur, Golaghat and Dibrugarh ${ }^{11}$, etc. with a few opening their own showrooms. The cluster's demand conditions are today well placed and promising.

\subsubsection{Industry Condition}

The Gems and Jewellery sector plays a significant role in the Indian economy, contributing around 7 per cent of the country's GDP and 15 per cent to India's total merchandise exports. It also employs over 4.64 million workers and is expected to employ 8.23 million by 2022. One of the fastest growing sectors, it is extremely export oriented and labour intensive. The sector is home to more than 300,000 players, with the majority being small players. Its market size is about US\$ 75 billion as of 2017 and is expected to reach US\$ 100 billion by 2025. It contributes 29 per cent to the global jewellery consumption. Gold demand in India rose to 523.93 tonnes between January to September 2018. India's gems and jewellery exports stood at US\$28.52 billion between Apr 2018 - Feb 2019 (IBEF, 2019). The demand for gold based Assamese jewellery is also very high as it is considered essential for wedding and most religious occasion.

\subsubsection{Institutional Conditions}

The cluster totally lacked the support of institutions, organisation or any government scheme/policies prior to the MSME CDP intervention. But through the soft intervention activities various convergences had been created with several institutions/department/centres, both formal and informal, from the national and local organisations, such as MSME, IIE, NID, DIC, DC (Handicraft), National Bank For Agriculture \& Rural Development (NABARD), State Institute of Rural Development (SIRD), The Housing Development Finance Corporation (HDFC), Industrial Development Bank of India (IDBI), AGVB, etc that had played and are still playing a supportive role in the cluster growth and survival.

So in an overall context, it is seen that though as per the Coolie's Framework not all conditions existed that were favourable, yet with most of the internal context being strong the other conditions could be created for the benefit of the cluster. In 2012, artisans from only 1 village was engaged in this activity and there were only 150 units which has now spread over to 3 villages with over 300 artisans, each with their own household units and 20 DIC registered units. Jewellery making has become a primary livelihood and the artisans had not looked back since then.

\subsection{Assessment based on Research Questions}

To further assess the economic sustainability of the cluster, we look into the data collected to answer two broad research questions:

a)Whether cluster interventions amongst home-based jewellery artisans of Ranthali has been able to provide a secured established livelihood.

b) Whether cluster interventions amongst home-based jewellery artisans of Ranthali has

11 Cities and towns of Assam 
enhanced their income \& been able to provide financial stability \& sustainability.

We study these aspects through the engagement/employment data, the production, income and investment data, raw material requirement and the sales turnover data.

\subsubsection{Engagement / Employment scenario}

Altogether there are about 300 artisans-cum owners in the Ranthali cluster who work in the jewellery making industry on a full time basis. The artisans are occupied all throughout the year as there is a continuous demand for their products. During peak season they work 24 hours a day making 80 to100 jewellery sets a month, taking short breaks only, and during off season they make 20 to 30 sets a month, when they work 8 hours a day.

Table 1: Number \& Type of Artisans

\begin{tabular}{|l|c|}
\hline Type of artisan & No. of artisans \\
\hline Owner-cum artisan & 300 \\
\hline Employee artisans & 412 \\
\hline
\end{tabular}

\subsubsection{Unit Formalization \& Income}

The cluster which had 20 artisans initially stands at 300 artisans today with their own household units. The number of micro units registered stands to 20 as in 2019.

\subsubsection{Investment and Income Scenario}

The investments of the business units include the fixed investment and the variable investment (working capital). The fixed investment includes investment on machinery and tools and on working shed. The average investment on tools and machinery for the cluster stand at Rs. 23,556/- per unit. And, the average investment on working shed is Rs. 36,000/- (IIE DPR, 2018). Besides, the average investment on the working capital requirement per month per business unit in the cluster is Rs.1,50,000/-.

These artisans have a monthly income of Rs 60,000/- to Rs 80,000/- per month. In addition to these there are about 412 permanently employed skilled artisans being employed by the units ( 2 to 5 numbers each), whose monthly salary ranges between Rs. $5000 /$ - to Rs. 10000/- depending on their skill.

Table 2: Investment Capacity

\begin{tabular}{|l|c|}
\hline Particulars & Average Investment \\
\hline Investment on machinery \& Tools & $23,556 /-$ \\
\hline Investment on working shed & $36,000 /-$ \\
\hline Investment on working capital & $1,50,000 /-$ \\
\hline Total Fixed Investment & $2,09,556 /-$ \\
\hline
\end{tabular}

Table 3: Annual Income

\begin{tabular}{|c|c|}
\hline No. of artisans & Annual Average Earning \\
\hline 300 & $600,000 /--960,000 /-$ \\
\hline 412 & $60,000 /--120,000 /-$ \\
\hline
\end{tabular}

With a minimum annual income of Rs 6 lakhs, monthly investment capacity of Rs 1,00,000/-to Rs 2,00,000/-, the ability to save, to meet household expenses comfortably, 
and invest back into the units shows that the cluster is economically sustainable and the artisans do not look for another occupation to meet daily requirements. All cluster artisans today have a bank account that they use for business and other monetary transactions.

\subsubsection{Annual Sales Turnover}

Though no research has been done till date on Ranthali jewellery artisans, this survey revealed that the market is robust. There is continuous demand for the gold based Assamese jewellery with the demand being highest during the months of November to March, which is the time when most marriages in Assam take place. Besides, with the increase in number of jewellery items and design variety and quality, the cluster artisans have a greater demand for their products, both in the local and state markets. Also, market linkages provided with several key jewellery houses in Guwahati has seen larger volume of orders being placed with the units having greater sustainability. The approximate total sales volume of the cluster is Rs. 75, 60,00,000/- per annum. The average monthly sales volume of a unit in the cluster stands at Rs 210,000 against an average monthly expenditure of Rs. 150,000/-. Table 4 represents the sales volume figure.

Table 4: Sales Turnover

\begin{tabular}{|c|c|c|}
\hline Avg. sales/month & Avg. exp/month & Avg. Profit \\
\hline $2,10,000 /-$ & $1,50,000 /-$ & $60,000 /-$ \\
\hline Total Sales/month (for 300 units) & Total exp/month & Total profit/month \\
\hline 6,30,00,000/- & $4,50,00,000 /-$ & $18,000,000 /-$ \\
\hline Total sales/year & Total exp/year & Total profit/year \\
\hline $75,60,00,000 /-$ & $54,00,00,000 /-$ & $21,60,00,000 /-$ \\
\hline
\end{tabular}

All figures are in Rupees

\subsubsection{Product profile}

The products that are manufactured in the cluster are categorized into three types of quality, based on the amount of gold content in the product. They are categorized as quality 1 (Q1) where the gold content is as high as $98 \%$., quality 2 (Q2) where the gold content is about $40 \%$. and quality 3 (Q3) where the proportion of gold: other metals is 25:75.respectively. Cluster interventions with NID since 2012 has helped the artisans produce 25-30 items with additional 70 different colour combinations from the initial 4-5 jewellery items the artisans made. Some of the major product range and the price range are shown in the table 5 below.

Table 5: Product Type \& Price Range

\begin{tabular}{|c|c|c|c|}
\hline \multirow{2}{*}{ Name of the Product } & \multicolumn{3}{|c|}{ Market Price Range (In Rupees) } \\
\cline { 2 - 4 } & Q1 & Q2 & Q3 \\
\hline Gejera set & $50,000-55,000$ & $5,500-7500$ & $3000-4500$ \\
\hline Doogdoogi & $40,000-45,000$ & $4000-4500$ & $3000-3500$ \\
\hline Loka-Paro & $50,000-55,000$ & $11,000-12,000$ & 5000 \\
\hline Thuria & 25,000 & $6000-7000$ & Do not produce \\
\hline Japi Locket & 25,000 & $13,500-15,000$ & 6500 \\
\hline Midang & $32,000-35,000$ & 7000 & 6000 \\
\hline Junbiri & 50,000 & 10,000 & 6,000 \\
\hline Madoli & $74,000-75,000$ & $6000-7000$ & 4500 \\
\hline
\end{tabular}




\subsubsection{Raw Materials- Requirement, source and price.}

Since, most of the units in the cluster produce the Q2 quality gold ornaments where the ratio of gold: silver mixture is approximately 40:60. Hence, apart from gold, silver also forms one of the most important raw materials. Besides, the other important raw materials include, various types of precious and semi precious gem stones, beads, 'tarsels' and 'moni', acids etc. The following table shows the approximate calculation of average amount of raw materials consumed by a business unit in the cluster.

Table 6: Raw Material Requirements

\begin{tabular}{|c|c|c|c|}
\hline Raw Material & Quantity required & Rate & Monthly requirement (In Rs.) \\
\hline Gold & 2 tola & $22400 /$ Tola & 44800 \\
\hline Silver & 15 tola & $355 /$ Tola & 5325 \\
\hline Hengul La & $250 \mathrm{gm}$ & $1250 / \mathrm{kg}$ & 312.5 \\
\hline Suhaga & $350 \mathrm{gm}$ & $1000 / \mathrm{kg}$ & 350 \\
\hline Mina & $750 \mathrm{gm}$ & $12 / \mathrm{gm}$ & 9000 \\
\hline Stones & $300 \mathrm{gm}$ & $94 / \mathrm{gm}$ & 28200 \\
\hline Moni & $400 \mathrm{gm}$ & $42 / \mathrm{gm}$ & 16800 \\
\hline Tarsels & 5 dozen & $120 /$ dozen & 600 \\
\hline
\end{tabular}

* All the calculations are based on per month consumption.

From all of the above it is seen that the cluster intervention under the MSE CDP scheme has been able to create several impacts in the Ranthali Jewellery Cluster from reviving the traditional skill of jewellery artisans to creating entrepreneurial set-ups and making the cluster an economically sustainable one. Most of the artisans of the village now have jewellery making as their primary livelihood as there seems to be a healthy growth of units, both households and micro, in the village since cluster formation, with a few expanding to starting their showroom in the cities.

\section{Ranthali Cluster Ecosystem}

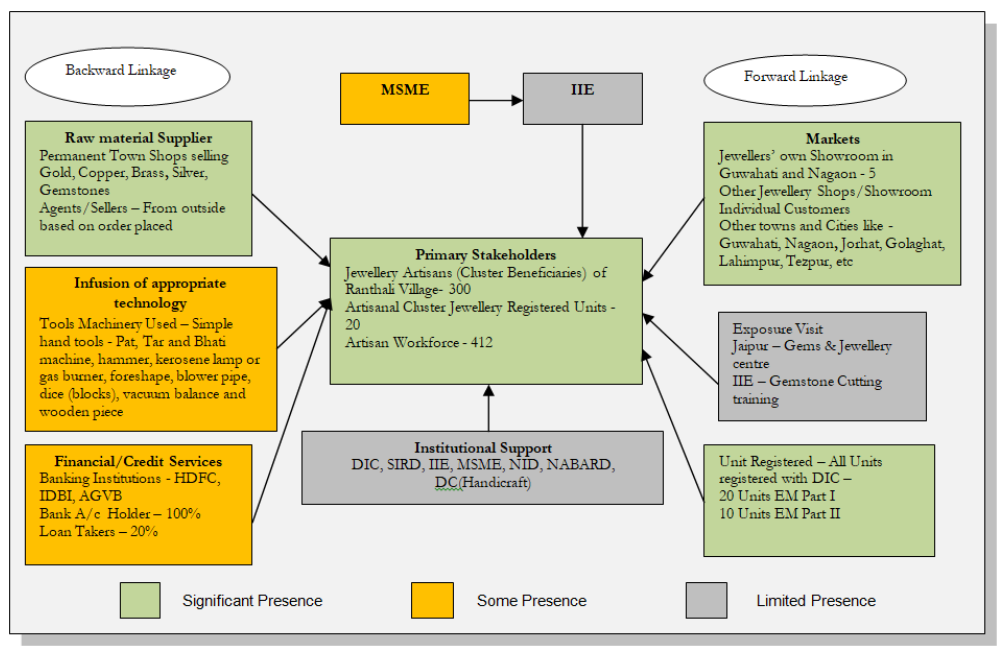

Figure 2: Ranthali Ecosystem

(C) 2019 The Authors. Journal Compilation 들 2019 European Center of Sustainable Development. 
The ecosystem created around the Ranthali cluster, today, reflects the exponential growth of the cluster in terms of the increase of the number of artisans, units, enhancement in income, in sales and in investment capacity. There has been more selfemployment and sustainability in the cluster. Due to a holistic approach and multiple convergences, the cluster today has a synergy of various stakeholders that has helped create an ecosystem where they are directly or indirectly involved in the growth and sustainability of the cluster, cooperating and co-existing together. However, there exists plenty of scope to capitalize on the synergies available for modernization of the cluster, keeping in mind the constantly changing buying behavior of customers who look for multi-designed and multiple usage of gold, precious stones and other fashioned products. Innovations and research on new designs, setting up of Quality Testing Centres, creating awareness on the developments taking pace elsewhere in the country and evolving measures to mitigate the shortcomings, etc are areas that need to be worked upon to protect the interest of the artisans of Ranthali cluster.

\section{Conclusion}

It is generally agreed that rural industries form the backbone of a developing country. The northeast states of India, with its rich tradition of indigenous crafts and industries and ample economic resources, has immense scope for the growth and sustained development of the small industries sector. However, despite the fact that it can play a pivotal role in the regional economy in terms of employment and economic growth, this potential has not been fully exploited. Hence, it is extremely important to mobilise this sector if we want economic progress. Therefore, clusters are increasingly recognized as the answer to an effective means of industrial development and promotion of small and medium size enterprises. Developing clusters is not only a means to improve the competitiveness of industry but also an instrument for alleviation of poverty, generation of sustainable employment, fostering innovation, infusing technology, enabling better credit flow and sustenance of environment issues more effectively and sustainably (Baruah, 2014).

\section{References}

Baruah, S. (2014). Report on Cluster Development Initiative in North East India: 2008-2014. Guwahati: Indian Institute of Entrepreneurship.

Beddig, C. (2008). Cluster Development Policy rooted in the Collective Efficiency Approach: Geneva: Graduate Institute of International \& Development Studies.

Bell, S., \& Morse, S. (2008). Sustainability indicators-measuring the immeasurable. London: Earthscan 2nd ed, $\mathrm{p}$ 5.

Clusters, F. f. (2006). Making Clusters Work UNIDO Methodology. New Delhi: Newstech Publishing Inc.

Datta, S., Mahajan, V., \& Thakur, G. (. (2004). A Resource Book for Livelihood Promotion. BASIX; New Economics Foundation; Ford Foundation.

DCMSME. June, 2015). bttp://wnw.dcmsme.gov.in/clusters/clus/ovrclus.htm. Retrieved from http://www.dcmsme.gov.in/clusters/clus/ovrclus.htm

Dictionary, A. H. (2016). Dictionary of the English Language. Houghton Miffin Harcourt Publishing Company. Retrieved from https://www.thefreedictionary.com/sustain

Foundation, I. B. (2019, May 20). Retrieved from www.ibef.org: https://www.ibef.org/industry/gemsjewellery-india.aspx 
Gait, E. (1926). A History of Assam. Calcutta: White Lotus.

Gomis, A., Parra, M., Hoffman, W., \& McNulty, R. (2011). Rethinking the concept of suatainability. Business Soc Rev, 173-174.

IBEF. (2019, May 28). India Brand Equity Foundation. Retrieved from www.ibef.org: https://www.ibef.org/industry/gems-jewellery-india.aspx

IIE DPR. (2018). Detailed Project Report. Guwahati: IIE.

Marshall, A. (1890). Principles of Economics. London \& New York: MacMillon \& Co.

Porter, M. (1998). On Competititon. Harvard Business Press. Retrieved from http://www.clustercollaboration.eu/cluster-definitions

Porter, M. E. (1998, November). Cluster and the New Economics of Competition. Retrieved 10 21, 2016, from http://www.Clusters and the New Economics of Competition - Harvard Business Review.htm

Singh, A. (2010). 2010 Clusters In India. Foundation for MSME Clusters(FMC). Retrieved August 3, 2015, from http://clusterobservatory.in/pub/cii.pdf

UNIDO. (2015, June). Indian Clusters. Retrieved August 12, 2015, from Overview of Clusters: http://www.dcmsme.gov.in/clusters/clus/ovrclus.htm 